\title{
The effect of partial reinforcement on extinction in avoidance conditioning ${ }^{\prime}$
}

\author{
GEORGE MARSH AND NED PAULSON, LEHIGH UNIVER- \\ SITY, Bethlehem, Pa. 18015
}

The effect of partial reinforcement on extinction was investigated in avoidance conditioning in which a nonreinforced trial was defined by delayed CS termination as well as shock ommission. Partial reinforcement significantly increased resistance to extinction. A group given conventional extinction with shock ommission but immediate response contingent $C S$ termination showed little decrement in responding.

The purpose of the present study was to investigate the effect of partial reinforcement on extinction in avoidance conditioning. Although the effect of partial reinforcement on extinction (PRE) has been intensely investigated in instrumental appetitive conditioning it has never to the authors' knowledge been investigated in avoidance conditioning. Probably the major reason for the lack of studies of this type was the difficulty in defining a nonreinforced trial in avoidance conditioning.

Early studies on the extinction of avoidance responding failed to obtain any reliable extinction at all (e.g., Brush, 1957; Robinson, 1961; Solomon, Kamin, \& Wynne, 1953). In these studies a nonreinforced extinction trial was defined only by the ommission of shock but the CS continued to be terminated promptly contingent on the response during extinction. Kamin (1956) has demonstrated that prompt response contingent CS termination is a powerful source of reinforcement in the acquisition of avoidance responding. Several studies with rats have shown that when prompt CS termination as well as shock is removed during extinction trials a rapid and reliable decrement in responding occurs (Haruki, 1959; Owen, 1963; Katzev, 1967). A secondary purpose of the present study was to replicate the effects of prompt or delayed CS termination on extinction in a different species.

\section{METHOD}

Subjects. The Ss were 18 goldfish approximately 1-2 in. long obtained from a local supplier.

Apparatus. The apparatus was a shuttlebox for small fish manufactured by the Lafayette Instrument Co. (Aquatic Conditioning Apparatus No. A-660). The existing control circuitry was modified so that the CS and UCS occurred on both sides of the apparatus at the beginning of a trial. The CS consisted of the illumination of two $7 \mathrm{~W}$ bulbs placed at both ends of the apparatus. The UCS was a $10 \mathrm{~V}$ ac intermittent shock delivered throughout the tank by plate electrodes. The experiment was run in a darkened room.

Procedure. Six Ss were randomly assigned to one of three groups prior to training. For the two continuous reinforcement groups the training procedure was as follows: The CS-UCS interval was $20 \mathrm{sec}$. If the $\mathrm{S}$ crossed to the opposite side of the tank within this interval the CS was terminated immediately and no shock was given. If the $S$ failed to make an avoidance response the shock came on and stayed on until the $S$ crossed over to the other side. The maximum shock duration was $15 \mathrm{sec}$ if the $\mathrm{S}$ failed to make an escape response.

In the partial reinforcement group the Ss were given reinforced and nonreinforced trials on a random $50 \%$ schedule. The procedure on a reinforced trial was the same as that described above for the continuous reinforcement groups. On a nonreinforced trial the shock was ommitted regardless of Ss' response latency and the CS was terminated $20 \mathrm{sec}$ after $S$ made a response. The maximum duration of the CS was $60 \mathrm{sec}$ if the $S$ failed to respond. All groups were given 50 trials of training with an intertrial interval varying between 5 to $50 \mathrm{sec}$. Response latencies were recorded to nearest second.

Extinction. In extinction one of the continuously reinforced groups was given conventional extinction in which the shock was ommitted on all trials but the CS was terminated immediately contingent on the response. The other continuously reinforced group was given combined extinction in which the shock was ommitted on all trials and the CS was terminated $20 \mathrm{sec}$ after the S's response. The partial reinforcement group also received the combined extinction procedure. All groups were given 50 extinction trials with the same range of ITIs used in training. The prompt CS termination procedure was reintroduced for 25 trials following extinction in the continuous reinforcement combined extinction group. This was to determine if the avoidance response could be reacquired when reinforced only with prompt CS termination after being extinguished to a low level.

Results. The training and extinction curves for the three groups are shown in Fig. 1. The mean number of avoidances for training and extinction in the three groups are shown in Table 1. An analysis of variance on the mean number of avoidances in the three groups during training was not significant $(F=1.28$, df $=$ $2 / 15, \mathrm{p}>.25$ ).

Extinction. An analysis of variance on the mean number of responses in extinction between the three groups was significant. $(F=136.00, d f=2 / 15, p<.001)$. A t test on the mean number of avoidances between the conventional and combined extinction groups was significant $(t=3.20 \mathrm{df}=10, \mathrm{p}<.01)$. A $\mathrm{t}$ test between the partial reinforcement group and the combined group was also significant $(t=2.23, d f=10, p<.05)$. A t test between the partial reinforcement group and the conventional group was not significant $(t=1.31, \mathrm{df}=10, p>.10)$. The mean number of avoidances for the last 25 trials of extinction in the combined group was 2.2. The mean number of responses for 25 reacquisition trials using CS termination only (no shock) was 13.8. This difference was significant $(t=3.14, d f=10, p<.01)$.

Discussion. Although the partial reinforcement group was somewhat below the continuous reinforcement group in training this difference was not significant. This outcome is in accord with the results of many instrumental appetitive conditioning experiments.

The present finding that little if any extinction occurs when the $\mathrm{CS}$ is promptly terminated with the response during extinction but that reliable extinction occurs when this source of reinforcement is removed is in accord with the results obtained in other species (Katzev, 1967). The present study in addition shows that partial reinforcement training in which a nonreinforced trial is defined by delayed CS termination as well as shock ommission will significantly increase resistance to combined or "true" extinction.

It appears evident that the PRE obtained in avoidance conditioning can not be explained by the "frustration" explanation commonly used to explain the PRE in instrumental appetitive

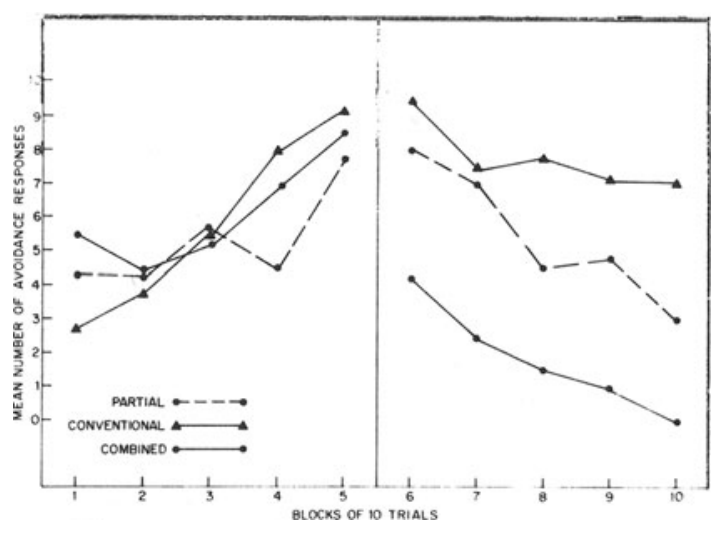

Fig. 1. Mean number of avoidances during training and extinction. 
Table 1

Mean Number of Avoidances

\begin{tabular}{lcc}
\multicolumn{1}{c}{ Group } & Training & Extinction \\
\hline Partial & 25.16 & 26.50 \\
Conventional & 30.00 & 39.00 \\
Combined & 30.83 & 9.16 \\
\hline
\end{tabular}

situations. It may be the case that the PREs obtained in appetitive and aversive conditioning are due to separate and independent processes. On the other hand a common mechanism may be involved in both situations. In the authors' opinion the most widely applicable theoretical explanation is some variant of the discrimination hypothesis.

\section{REFERENCES}

BRUSH, F. K. The effects of shock intensity on the acquisition and extinction of an avoidance response in dogs. J. comp. physiol Psychol, $1957,50,547-552$.
HARUKI, Y. A consideration of extinction procedure of avoidance response. Annu. anim. Psychol., (Japan) 1959, 9, 53-61.

KAMIN, L. J. The effects of termination of the CS and avoidance of the US on avoidance learning. J. comp. physiol. Psychol, 1956, 49, 420-424.

KATZEV, R. Extinguishing avoidance responses as a function of delayed warning signal termination. J. exp. Psychol., 1967, 75, 339-344.

OWEN, S. The effect on avoidance response extinction in rats of CS continuation and emotional constitution. J. genet. Psychol., 1963, 103, 147-151.

ROBINSON, H. G. Persistence of a response in the apparent absence of motivation. J. exp. Psychol, 1961, 61, 480-488.

SOLOMON, R. L., KAMIN, L. J., \& WYNNE, L. C. Traumatic avoidance learning. The outcomes of several extinction procedures with dogs. $J$. abnorm. soc. Psychol, 1953, 48, 291-302.

\section{NOTE}

1. This study was supported in part by Grant No. MH-18104-01 from NIMH to the first author. The authors would like to thank Richmond Johnson for assistance in running some of the Ss. 